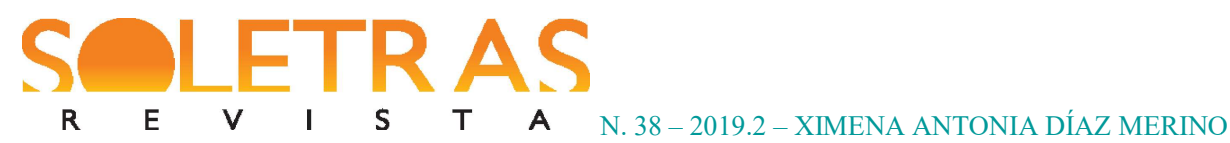

\title{
Nueva corónica y buen gobierno i justicia: textualidades, subversión y resistencia en "zonas de contacto"
}

\author{
Ximena Antonia Díaz Merino ${ }^{1}$
}

Resumen: Los primeros textos de autoría indígena en Hispanoamérica constituyen parte importante del corpus literario colonial, pues se localizan en las denominadas zonas de contacto, es decir, en los "[...] espacios sociales en que culturas dispares se encuentran, chocan y se enfrentan, a menudo dentro de relaciones altamente asimétricas de dominación y subordinación [...].”(PRATT, 2010, p. 31). Dentro de ese contexto será analizada la crónica de Felipe Guaman Poma de Ayala titulada Nueva corónica y buen gobierno i justicia (1615), considerada una de las primeras fuentes escritas por un indígena que narra su propia versión de la historia andina. Las reflexiones presentadas aquí convergen para la idea de que el cronista ameríndio elaboró una obra autoetnográfica permeada de críticas al sistema colonial y de reivindicaciones de justiça social manifestadas en un documento escritoen lengua española y quéchua, en el que se fusiona la escrituraylaoralidade. Un manuscritocomplementado con ilustraciones y epígrafes explicativas con el intuito de traducir el imaginario andino a un público europeo y dedivulgar su propuesta de reforma administrativa colonial.Estudios críticos como los de Wachtel (1973), Pratt (2010), Porras Barrenechea (1948), Adorno (2010) y González Echevarría (2011) subsidiarán los análisis de este estudio.

Palabras clave: Literatura Colonial Hispanoamericana, Felipe Guaman Poma de Ayala, Nueva Crónica y Buen Gobierno

Cada manuscrito es único - así como su representación oral-.Es el trabajo de uno o más indivíduos humanos. Ambos procesos corresponden a su medio ambiente, varian con el tiempo y de acuerdo a las circunstancias [...] Los textos escritos a mano, como produtos, se parecen al libro mecanicamente reproducido; el processo de su creación imita la naturaleza única de su tradición oral y del performace oral. La naturaleza retórica de la oralidad, también, se extiende al reino del texto manuscrito, siempre condicionada y elaborada de acuerdo con su circumstantiae... El texto manuscrito está constituídopor los indivíduos que lo crean [...]. (DAGENAIS, 1994, p. 17)

\footnotetext{
${ }^{1}$ Doutora e Mestre em Letras Neolatinas opção Literaturas Hispânicas pela Universidade Federal do Rio de Janeiro. Professora Adjunta de Cultura e Literaturas Hispânicas do departamento de Letras do Instituto Multidisciplinar da Universidade Federal Rural do Rio de Janeiro (UFRRJ). Rio de Janeiro, Brasil. E-mail: ximenadm2@gmail.com (iD https://orcid.org/0000-0002-8297-3118
} 


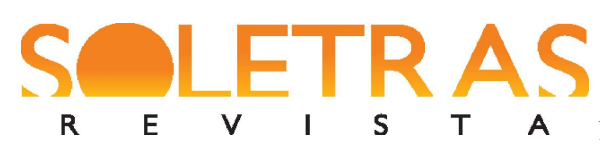

El texto colonial indígena revela una perspectiva propia, diferente del discursode los cronistas europeos, y apresenta una nueva versión de la historia. Conforme Pratt (2010, p. 3536), esos escritos pueden ser considerados textos 'autoetnográficos', puesto que en ellos “[...] los sujetos colonizados emprenden su propia representación de manera que se 'comprometen' con los términos del colonizador". Llevando en consideración que en los textos etnográficos los europeos representan para sí mismos la cultura observada, Pratt añade que los textos autoetnográficos "[...] son los [textos] que los otros construyen para responder a esas representaciones metropolitanas y para dialogar con ellas". Son textos direccionados tanto a lectores metropolitanos como a lectores del propio grupo social del escritor que revelan “[...] relatos de la dominación imperial y de la resistencia vistos desde el lugar mismo en que ocurrían”. En las palabas de José Antonio Mazzotti (1996, p. 20) se trata de textos que surgieron "[...] como respuesta a diversas tendencias ideológicas manifestadas en las historias sobre el Nuevo Mundo en función de intereses propios de un sujeto colonial dominante”.

Los primeros textos de autoría indígena en Hispanoamérica constituy en parte importante del corpus literario colonial, pues se situanen las denominadas zonas de contacto, es decir, en los "[...] espacios sociales en que culturas dispares se encuentran, chocan y se enfrentan, a menudo dentro de relaciones altamente asimétricas de dominación y subordinación, tales como el colonialismo, la esclavitud [...]" (PRATT, 2010, p. 31). De acuerdo con Mary Louise Pratt, las zonas de contacto constituyen espacios sociales propicios para que las culturas originarias enuncien su versión de la historia y construyan su identidad, ya que

La zona de contacto desplaza el centro de gravedad y el punto de vista hacia el espacio y el tiempo del encuentro, al lugar y al momento en que individuos que estuvieron separados por la geografia y la historia ahora coexisten en un punto, el punto en que sus respectivas trayectorias se cruzan [...] los individuos que están en esta situación se constituyen en y a través de su relación mutua [...]. (PRATT, 2010, p. 34)

Cabe destacar que la antropología se tornoun discurso hegemónico en la narrativa latinoamericana en elsiglo $\mathrm{XX}$, perola disciplina tuvo su inicio en el periodo del 


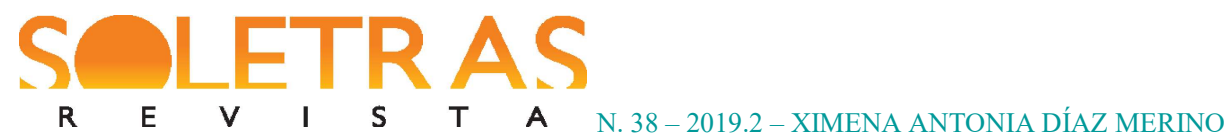

“descubrimiento" de América cuando en 1494 Cristóbal Colón dejó al monge catalán Ramón Pané en la isla La Española con la misión de aprender la lengua indígena taíno y de registrar el cotidiano local. Los registros de Pané constituyen, de acuerdo con González Echevarría (2011, p. 208)

[...] el principio de una campaña polémica y vasta para adquirir conocimientos sobre las poblaciones nativas del Nuevo Mundo, realizada en los siglos XVI y XVII, tanto por miembros de órdenes religiosas como por funcionarios del gobierno tal el cronista mayor.

En esa época fueron producidos documentos sobre las riquezas de las civilizaciones indígenas americanas, como los registros de los frailes Bartolomé de Las Casas y Bernardino de Sahagún. Conel pasar del tiempo surgieron escritores indígenas y mestizos como Alba Ixtlilcóchitl, Inca Garcilaso de la Vega y Felipe Guaman Poma de Ayala, que se preocuparon en registrar las características de sus culturas a partir de sus propias vivencias. Esos documentos forman parte "del intercambio de documentos legales que prevaleció durante el período colonial. Era la única forma de decir lo que tenían que decir y la manera más efectiva de dar a sus escritos un imediato efecto político." (GONZÁLEZ ECHEVARRÍA, 2011, p. 209-210).

En ese contexto, la crónica en forma de carta de Felipe Guaman Poma de Ayala (¿1530s-1616?) titulada Nueva corónicay buen gobierno i justicia, datada en Cuzco en el año 1615 que tenía como destinatario el rey Felipe III de España, puede ser considerada una de las primeras fuentes escritas por un indígena que narra su propia versión de la historia andina.

De acuerdo con las informaciones del manuscrito, Guaman Poma era descendiente, por parte paterna, de la dinastía Yarovilca Allauca Huánacoy, por parte materna, de los Incas. Vivió en Perú durante el primer siglo colonial hispanoamericano. Se autodenominó indio ladino, es decir, un indígena capacitado en el idioma español, dominaba también otras lenguas locales, habilidad que lo tornó traductor. Los traductores fueron fundamentales para la acción colonizadora, pues realizaban una función mediadora entre conquistadores y conquistados y 


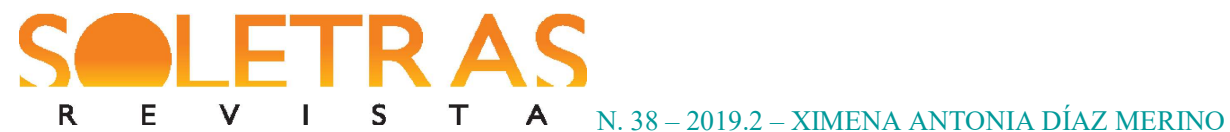

desenvolvían un papel importante en la interacción de códigos culturales, de identidades y de alteridades en la sociedad colonial.

Como consecuencia de sus habilidades linguísticas, Guaman Poma desenvolvió la función de escritor e intérprete para la administración y jurisprudencia española, pues como afirma Rolena Adorno (2010, p. 1) "sirvió de asistente al visitador eclesiástico Cristóbal de Albornoz en las campañas contra el Taki Unquy, ${ }^{2}$ el movimiento nativista cuyos fines eran la destrucción del dominio cultural europeo y la restauración de los dioses andinos." Y añade que tuvo "un contacto intenso y probablemente prolongado con instituciones eclesiásticas." Experiencias que le posibilitaron conocer la lógica de los conquistadores y de sus estrategias de dominación. Guaman Poma reconoce que participó en las primeras campañas de extirpación de idolatrías bajo el comando de Albornozy relata que su función era identificar a los indígenas que praticaban ritos antiguos, y declaró "Todo lo escrito de los pontífises lo sé porque fue sirviendo a Cristóbal de Albornós, uecitador general de la santa madre yglecia, que consumió todas las uacasýdolos y hecheserías del rreyno. Fue cristiano jues." (POMA DE AYALA, 1615, p. 282). Sobre la personalidad del visitador Albornoz, Guaman Poma escribió

Éste fue brabojues y castigó a los padres cruelmente, a los soberbiosos y castigó a los demonios, guacas ýdolos de los yndios. Y lo quebró y quemó y corosó a los hicheserosyndios, yndias y castigó a los falsos hicheseros y taquioncoy [...] De todo castigó este brabo jues. (POMA DE AYALA, 1615, p. 690).

Se comprende, por lo relatado en el manuscrito, que la función de Guaman Poma como asistente del visitador Albornoz consistía en identificara los indígenas que praticaban la idolatría, práctica que la iglesia prohibia, y también servía de interlocutor entre los hablantes del quechua y los hablantes de español, como ilustrado en el dibujo titulado "CAPÍTVLO PRIMERO DE VECITADOR: CHRISTÓBAL DE ALBOR nós, uecitador general de la santa

\footnotetext{
${ }^{2}$ Movimiento religioso y político que surgio en 1565 , año en que se desarrollabalaresistencia indígena contra la conquista española. Su objetivo principal era restaurar el culto a lashuacas, antiguas ceremonias de bailes (taquis), los sacrificios de llamasy el culto secreto de losconopas o amuletos de piedra.
} 


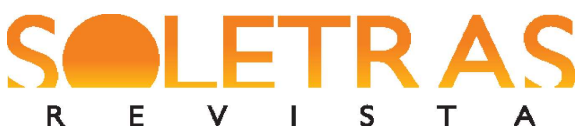

madre yglecia, buena justicia.” (POMA DE AYALA, 1615, p. 689), en el que Albornoz supervisiona el castigo a un indígena.

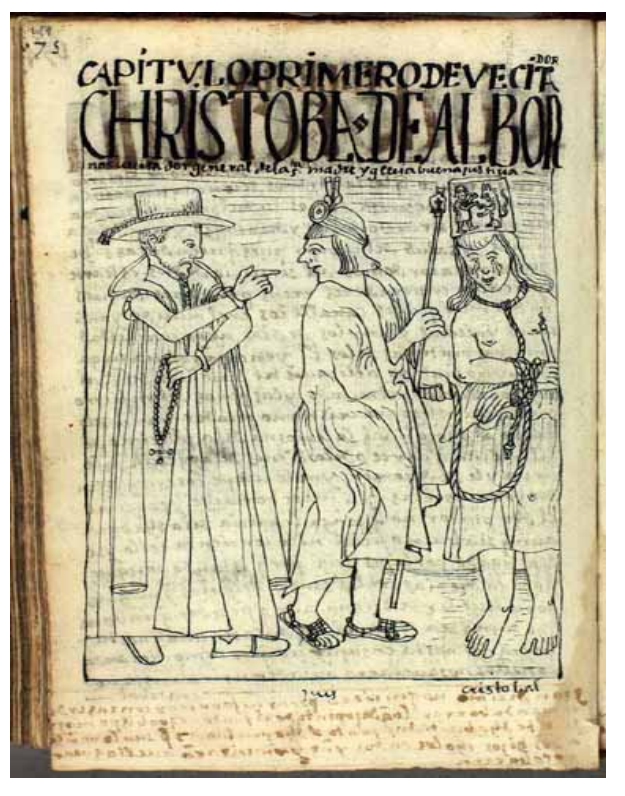

I Poma de Ayala (1615, p. 689)

De esa forma, el cronista ameríndio puede ser considerado un traductor de culturas que, por haber sido educado tanto en la matriz andina como en la europea del Perú colonial, poseía conocimento de las dosculturas, estado que le permitió realizar su obra mayor: la Nueva corónica $i$ buen gobierno que consiste en traducir y codificar el imaginario andino para un público europeo. Para realizar tal tarea utilizó herramientas tanto del colonizador como de su cultura, como la iconografía europea y la andina; la escritura alfabética en español y la transcripción de dialectos andinos. De esa manera produjo una de las primeras crónicas bilíngues escritas por un indígena incorporado a la cultura occidental sin

perder su esencia indígena.

En la Nueva corónica y buen gobierno i justicia, texto constituído por 1200 páginas y 398 dibujos, Guaman Poma de Ayala desenvuelve una interpretación crítica del imperio español y propone un sistema de gobierno más adecuado a la realidad peruana colonial. Este documento ofrece al monarca un panorama de la sociedad andina antigua hasta el reinado de los Incas y informa sobre la crisis provocadapor la colonización española. El manuscrito se divide en la Nueva Corónica, que aborda la história andina hasta la llegada de los españoles, y el Buen Gobierno, que evoca los eventos posteriores a la conquista y hace un análisis crítico de la colonización y de la situación impuesta a los indígenas.

La importancia de la crónica de Poma de Ayala está en la escritura elaborada bajo la perspectiva del sujeto colonial originario del Tawantinsuyuy no bajo la perspectiva del sujeto europeo que no comprendía la lengua ni la subjetividad del hombre andino. El cronista indígena abrió camino para el "pensamiento otro", para el pensamiento fronterizo a partir de la experiencia y de la memoria del Tawantinsuyu: nombre en lengua quechua del Imperio Inca, que significa "las cuatro regiones juntas". En el "MAPA MVNDI DEL REINO DE LAS 


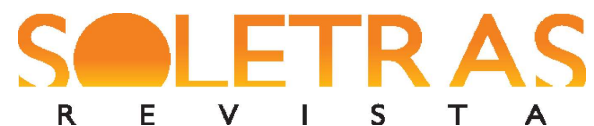

N. 38 - 2019.2 - XIMENA ANTONIA DÍAZ MERINO

IN[DI]AS" dibujado por Guaman Poma, se puede observar la división cuadripartida del Tawantinsuyu (POMA DE AYALA, 1615, p. 983-984).

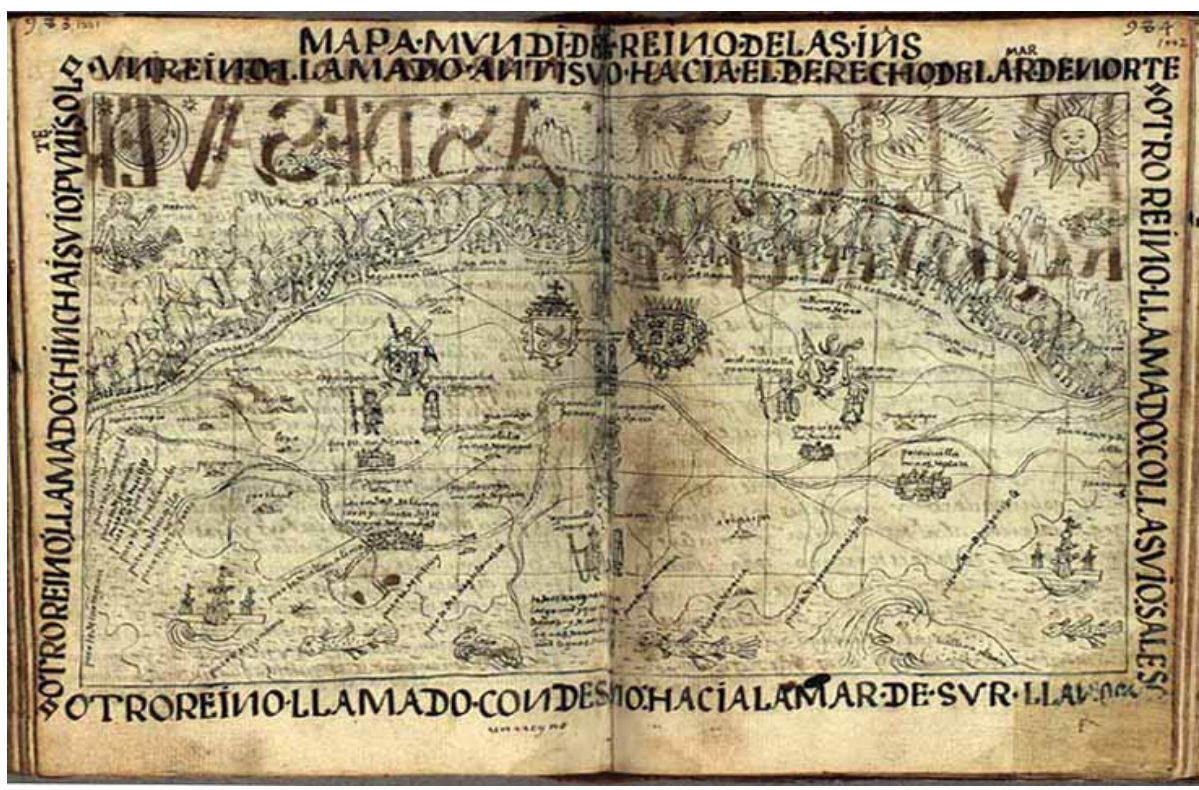

II Poma de Ayala (1615, p. 983-984)

El mapa representa el Tawantinsuyu dividido en cuatro regiones que corresponden a los cuatro puntos cardinales, una imagen arquetípica de la organización andina complementada con los símbolos del imperio español. Para Nathan Wachtel (1973, p. 177) "Este mapamundi sintetiza en uno solo tanto el Mundo Viejo como el Nuevo de las Yndias del Perú".

La propuesta de Guaman Poma se revela en el título de su obra: Nueva Crónica i Buen Gobierno. Una nueva crónica era necesaria porque las escritas por castellanos presentaban deficiencias en lo que se refiere a la reflexión realizada sobre la nueva región y la nueva cultura con que se depararon. Una realidad que el europeo no podría comprender ni explicar a partir de su propia visión de mundo. Propone también un "Buen Gobierno" como espacio de coexistencia, de igualdad con Castillay con las comunidades del Tawantinsuyu, propuesta que entraba en conflito con la política europea: un régimen monárquico y capitalista-mercantil que no consideraba la posibilidad de una coexistencia armónica como la proclamada por Guaman 


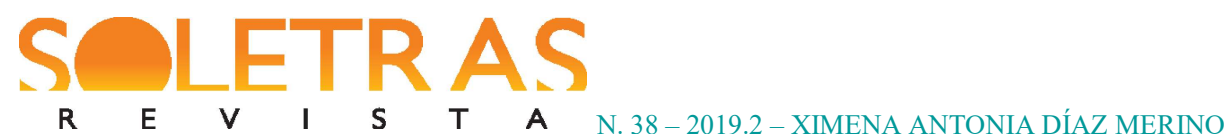

Poma. La crónica del escritor amerindio permaneció ignorada en el archivo de los reyes de la Biblioteca Real de Copenhague en Dinamarca por aproximadamente trescientos años.

De acuerdo conel historiador peruano Raúl Porras Barrenechea (1948) el manuscrito habríal legado a la Biblioteca Real de Copenhague después de ser "remitido a España para ser conservado en las cámaras imperiales, como una expresión curiosa de las civilizaciones primitivas de América" y también comenta que en la biblioteca de Gaspar de Guzmán y Pimentel, hombre de confianza del rey Felipe IV entre 1622 y 1643, había numerosos manuscritos de América, entre los que estaría el manuscrito de Guaman Poma. Esa biblioteca, según el historiador peruano "fue comprada, en parte, por Cornelius Pederson Lerche, quien fue embajador danés en Madrid en 1650-53 y quien residió en dicha ciudad hasta 1662. Este los llevó a Dinamarca."

El manuscrito extraviado fue encontrado por el peruanista Richard Pietschmannen 1908. A partir de los primeros estudios sobre la obra se comenzó a cuestionar el valor eurocéntrico y la fuerza del colonialismo en la creación del mundo moderno, ya que de acuerdo con Porras Barrenechea (1948)

[...] los estudos de Pietschmann publicados en Nachrichtende la Real Sociedad de Goettingen, en 1908 y en las Actas del Congreso de Americanistas de Londres de 1912, revelaron la importancia del cronista autóctono y hasta entonces totalmente ignorado. Este no pudo ser cabalmente conocido e interpretado en el Perú, sino a partir de 1936, en que el manuscrito de Huamán Poma fue publicado en edición facsímil por el Instituto de Etnología de París.

Después de la divulgación del manuscrito de Poma de Ayala, los críticos latinoamericanos, al estudiar el texto, constataron que el discurso europeo sobre América ya venía siendo cuestionado desde el período colonial, configurando un proceso de reinvención del imaginario americano bajo la perspectiva de un indígena ladino. Un proceso libertador que, según Pratt (2010, p. 26), ocurre porque "las transiciones históricas importantes alteran la manera en que la gente escribe porque alteran sus experiencias y, con ello también su manera 


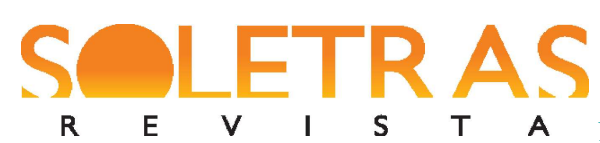

de imaginar, sentir y pensar el modo en que viven", de esa forma las modificaciones presentadas en la expresión literaria revelan esos cambios ideológicos a lo largo de la historia.

Durante el periodo colonial era una práctica comúnen la élite indígena y española escribir peticiones y demandas, como las de Guaman Poma, destinadas a la Corona. En las colonias españolas la palabra escrita se convirtió en fuente de legitimidad, pues los referenciales históricos reconocidos en la cosmovisión española eran transmitidos de forma escrita. De esa manera la palabra escrita modificó la concepción de mundo de los amerindios y constituyó un elemento fundamental en la formación de la sociedad colonial americana, puesto que la participación de intelectuales indígenas alfabetizados posibilitó según Rappaport (2016, p. 30) la

inscripción visual y alfabética entre los pueblos nativos de los Andes [...] que involucra una compleja constelación de canales de expresión tanto visuales como alfabéticos, que funcionaban en el mundo colonial andino dentro de un sistema ideológico que los veia como inextricablemente interconextados y como herramientas primordiales para reorganizar las cosmovisiones y las vidas de los índios suramericanos.

Se constata de esa forma, la importancia de la alfabetización y del letramiento desarrollado por los europeos en las colonias, pues mientras la alfabetización es el proceso de aprendizaje en el que se desenvuelve la habilidad de leer y escribir, el letramiento desenvuelve el uso competente de la lectura y de laescritura en las prácticas sociales. O sea, el alfabetizado sabrá codificar y decodificar el sistema escrito, yel sujeto letrado llegará más alla, siendo capaz de dominar la lengua en su día a día en diversos contextos. Para Rappaport (2016, p. 31), la introducción de la alfabetización letrada en las sociedades orales americanas fue realizada con el objetivo de dominación, ya que

las implicaciones de la alfabetización letrada y visual está indisolublemente unida con un análisis de la dominación colonial española y con la manera en que la escritura y las expresiones pictórica funcionaban como una vara para medir la jerarquía cultural de un mundo colonial y como un vehículo para la 


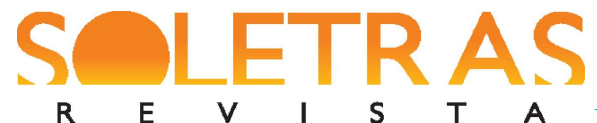

incorporació de los pueblos nativos en el projecto colonial. (RAPPAPORT, 2016, p. 31).

Componentes importantes en la construcción del discurso colonial fueron los sistemas de representación alfabética y visual, los cuales estaban íntimamente relacionados con las prácticas didácticas, religiosas y legales de los europeos en América, configurando un proceso de letramiento que contribuyó en la constitución de las instituciones europeas de las sociedades indígenas. Por lo tanto, conocer las bases de ese discurso hace posible la comprensión de los procesos de formación colonial entre los siglos XVI al XVIII. El letramiento se tornó indispensable tanto para la expresión colonizadora como para la colonizada, puesto que configuró un espacio simbólico en el que los europeos implementaron una política de colonización y conversión al cristianismo, y al mismo tiempo, los propios colonizados pudieron, através del letramiento, “describirse, textualmente y presentarse visualmente por sí mismos ante sus colonizadores y presionar por sus demandas en la arena política." (RAPPAPORT, 2016, p. 45). Sobre la importancia de la palabra escritaen las colonias españolas Ángel Rama (1998, p.32) explica

En el centro de toda ciudad, según diversos grados que alcanzaban su plenitud en las capitales virreinales, hubo una ciudad letrada que componía el anillo protector del poder y el ejecutor de sus órdenes: una pléyade de religiosos, administradores, educadores, profesionales, escritores y múltiples servidores intelectuales, todos esos que manejaban la pluma, estaban estrechamente asociados a las funciones del poder [...]".

En el periodo colonial muchos grupos subordinados se familiarizaron con actividades como la copia y la elaboración de documentos e imágenes bajo el direccionamiento de grupos dominantes. Esa práctica provocó el surgimiento de especificidades dentro de la cultura y de la sociedad colonial, así la producción ortodoxa de imágenes se transformó en heterodoxa, de forma que una misma imagen pasó a tener diversas interpretaciones dependiendo de los miembros de las diferentes tradiciones culturales que tuviesen acceso a ellas. En las palabras de Mary Luise Pratt (2010, p. 34) se trata de la utilización que hacen los conquistados de las 


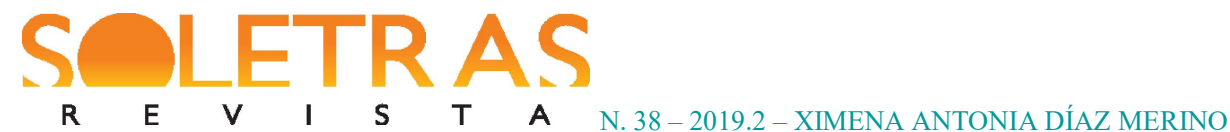

estructuras ideológicas y culturales que les fueron impuestas por los conquistadores por medio del lenguaje, como resultado de la "presencia simultánea, de interacción, de conceptos y prácticas entrelazadas, algo que a menudo se da dentro de relaciones de poder radicalmente asimétricas."

En ese contexto debe ser enfatizado "el rol crítico de la escritura como el escenario donde toman lugar las diferencias sociales y la apropiación de formas culturales, en particular en las luchas que rodean la producción del discurso legal. En el contexto colonial, tales luchas frecuentemente tomaron lugar en los documentos manuscritos." (PAPPAPORT, 2016, p. 41).

Los manuscritos coloniales constituyen, por lo tanto, objetos de alfabetización letrada producidos dentro de las comunidades indígenas coloniales. La realización de un manuscrito era una actividad muy peculiar y muchas veces llegó a ser tema de representación pictórica en los manuscritos coloniales, como podemos constatarlo en el

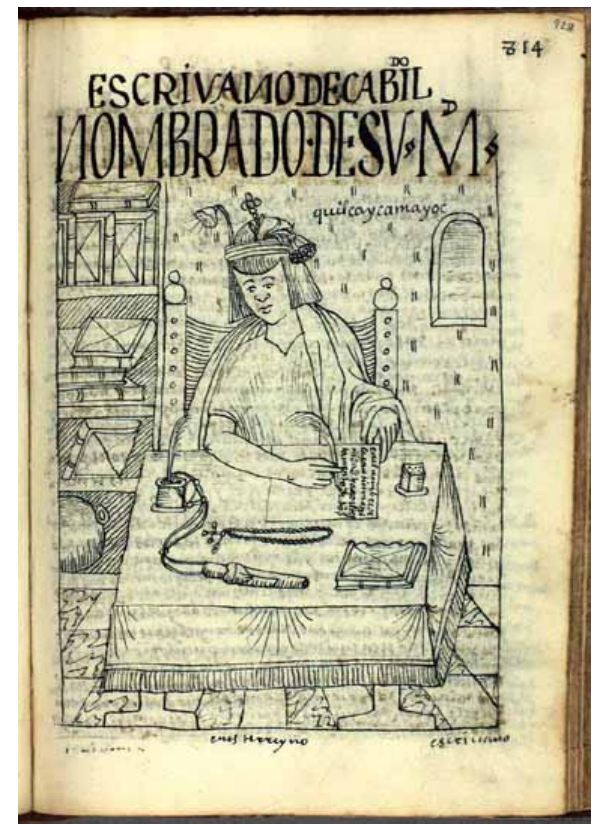

III Poma de Ayala (1615, p. 828) capítulo titulado "De los administradores locales andinos en este reino", de la crónica de Poma de Ayala, en el que consta el dibujo de un escribano nativo denominado "ESCRIVANO DE CABILDO NOMBRADO DE SU M[AGESTA]D, quilcaycamayoc" (POMA DE AYALA, 1615, p. 828). Quilcayes una palabra quechua que significa escribir, dibujary pintar, Poma de Ayala identificó al escribano indígena como un quilcamayo, o sea, un "hacedor de la escritura” (RAPPAPORT, 2016, p. 45), que en una actitud reflexiva y solitaria realiza su ofício en un espacio que reproduce un escenario europeo: una sala con mesa, silla, plumas, tintero y hoja de papel, entre otros utensilios y documentos.

Al reflexionar sobre la acción del escritor indígena que realiza el acto de escribir con las mismas herramientas utilizadas por el europeo, se constata que ese intelectual creó un texto diferente, pues Poma de Ayala, además de presentar en su manuscrito una mezcla de quechua con español, creó ilustraciones con epígrafes explicativas, recurso muy utilizado por el europeo. En la crónica de Guaman Poma la escritura y el dibujo se 


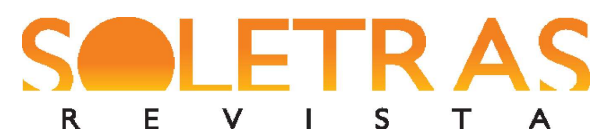

N. 38 - 2019.2 - XIMENA ANTONIA DÍAZ MERINO

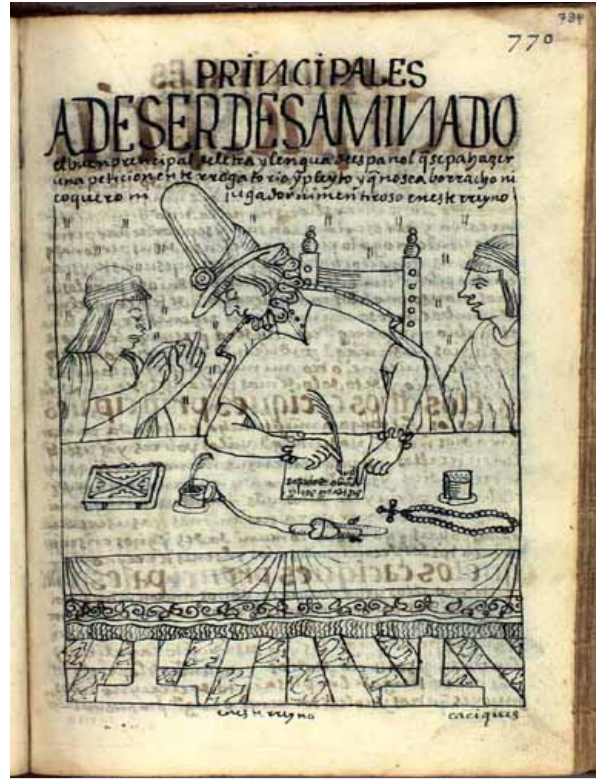

IV Poma de Ayala (1615, p. 784)

usionan configurando un texto en el que se puede observar la transformación de la oralidad en escritura, constituyendo un duplo proceso traductorio, puesto que “el testimonio se produce en la 'lengua madre' pero se inscribe en español.” (RAPPAPORT, 2016, p. 49). Ese proceso de traducción puede ser observado en el dibujo titulado "Principales", parte constitutiva de "El capítulo de los príncipes, señores principales y otros cargos hereditarios andinos." (POMA DE AYALA, 1615, p. 784), imagen que revela unescrivanoen el momento preciso de la transformación de la oralidad en escritura, porque de forma simultánea, escucha las declaraciones del miembro de su comunidad en quechua mientras que, con la mano izquierda, sujeta una hoja de papel y, con la mano derecha, escribe en español lo que está oyendo. En ese dibujo Poma de Ayala escribió “A DE SER DESAMINADO el buen prencipal de letra y lengua de español que sepa hazer una petición, enterrogatorio y pleyto y que no sea borracho ni coquero ni jugador ni mentiroso en este rreyno".En la epígrafe queda definida la función del "peticionario" que usa la palabra escrita como medio de reivindicación social.

Por lo tanto, se constata que a partir de la alfabetización letrada implementada en la región andina, intelectuales indígenas como Guaman Poma comenzaron a elaborar su propia interpretación de los hechosy, con frecuencia, utilizaron herramientas europeas, realizando un proceso de transculturación, resultado de la reelaboración y utilización de los materiales proporcionados por la cultura dominante, constituyendo la expresión de los colonizados. La emergencia de esta visión andina "otra" está anclada en la traducción o interpretación de las categorías culturales europeas y americanas que entraron en contacto y que presentaron las tensiones propias de una sociedad colonial en crisis. Fue en ese escenario que Guaman Poma escribió su obra teniendo que lidiar con una fuerte interferencia lingüística y semiótica, como destaca Viereck Salinas (s/d, p. 87), al registrar que Guaman Poma 


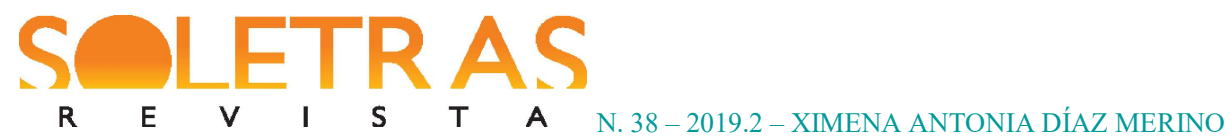

[...] funda su escritura en un ejercicio de traslación de la lengua indígena (principalmente el quechua) y la oralidade andina (visión andina) hacia el castellano y la escritura alfabética, pero ajustándose a los requerimentos de la lengua y el código oral de partida.

El cronista amerindio consideraba importante la alfabetización en castellano y registró en su manuscrito la necesidad de que los nativos aprendiesen a leer y a escribir, como transcrito a seguir:

Que los dichos maystrosan de enseña[r] los muchachos, niños, niñas, mosos y las donzellas, que a los muchachos en la escuela y a las niñas y donzellas en sus casas. Se le tome lición y le enseñe a leer y [e]scriuir para que sean cristianas y que tengan ojo y ánima para el cielo[...].

Y, ci pudiere, en pueblo grande ochicaayga escuela y cristiandad y pulicía en todo este rreyno, aunque no quiera los padres y caciques, corregidores. A de auer cristiandad en este rreyno. (POMA DE AYALA, 1615, p.685).

De la experiencia de Guaman Poma se depreende que la convivencia de culturas en un mismo territorio resulta en una mediación entre las respectivas lenguas envueltas y las diferentes visiones de mundo de los grupos humanos en contacto. Esa interacción se revela en acciones comunicativas recíprocas en las que son activados diferentes códigos que transforman la realidad tanto de los conquistados como de los conquistadores.

Poma de Ayala utilizó en la redacción de la Nueva corónica y buen gobierno tanto la lengua castellana como su lengua materna, además de diversos dialectos que aprendió en sus viajes por el territorio andino, lo que le permitió tener una visión real de la vida en la colonia y recoger diversos testimonios por donde pasaba. En la "Carta del autor a don Felipe", iten que corresponde a la "Presentación" de la primera parte de la crónica, Poma de Ayala explica la dificultad que tuvo para escribir las historias que componen su texto porque las informaciones que colectó no tenían registros escritos. Informa también que relatará la historia de su pueblo desde el primer indio hasta la llegada de los españoles y los daños que causaron a su pueblo

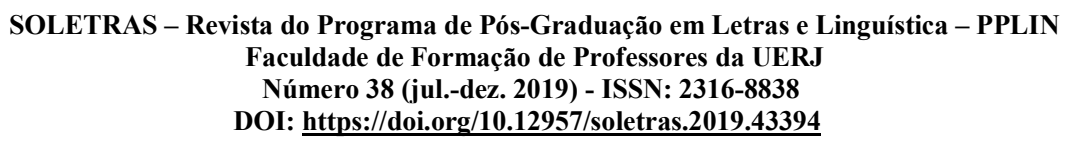




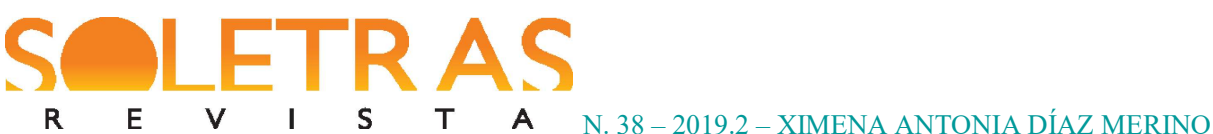

[...] para sacar en limpio estas dichas historias hube tanto trabajo por ser sin escrito ni letra alguna sino nomás de quipos y memorias y relaciones de los índios antiguos de muy viejos y viejas, sábios testigos de vista [...] me determine a escribir la historia y descendencia y los famosos hechos de los primeiros reyes y señores y capitanes, nuestros abuelos y de sus principales y vidas de índios y sus generaciones y descendencia desde el primero índio [...] de los daños de los españoles en el tiempo del Emperador y después de la conquista de este vuestro reino de las Indias del Perú [...] He tratado de haber para este efecto las más verdaderas relaciones que me fueron posibles tomando la sustancia de aquellas personas, aunque de varias partes me fueron traídas [...]. (POMA DE AYALA, p. 7-8)

En la "Presentación" el autor le explica al rey Felipe III que utilizó dibujos en la composición de su carta con el objetivo de tornar menos cansativa la lectura

pasé trabajo para sacar con el deseo de presentar a Vuestra Magestad este dicho libro intitulado Primer Nueva Crónica de las Indias del Perú y provechoso a los dichos fieles cristianos, escrito y dibujado de mi mano e ingenio, para que la variedade de ellas y las pinturas y la invención y dibujo haga fácil aquel peso y moléstia de una lectura falta de invención y de aquel ornamento y pulido estilo que en los grandes ingenios se hallan [...]. (POMA DE AYALA, p. 8-9)

En el "Prólogo al lector Cristiano" el cronista relata el uso de diversas lenguas locales, además del castellano, e insiste en la dificultad que tuvo para narrar esas historias, pues estas no poseían fuente escrita

[...] ser sin escrito ni letras alguna sino no más que quipos y relaciones de muchos lenguajes, ajuntando con la lengua castellana y quíchua, ingá, aymara, puquina, colla, canche, cana, charca, chinchaysuyo, andesuyo, collasuyo, condesuyo, todos los vocablos de indios, que pasé tanto trabajo por ser servicio de Dios nuestro señor y de su Sacra Católica Majestad rey don Felipe 


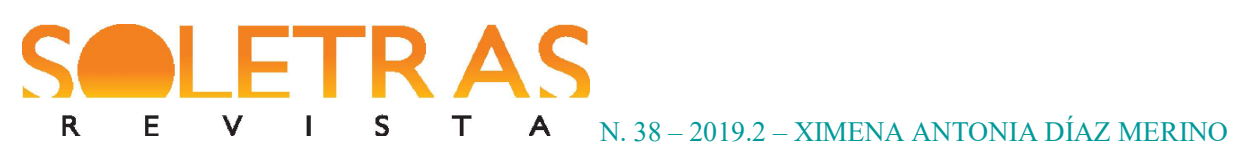

el tercero gasté mucho tempo y muchos años acordándome que há de ser provechoso a los fieles cristianos [...] (POMA DE AYALA, p. 9)

Por haber trabajado para la administración y jurisprudencia española, Guaman Poma tuvo acceso tanto a documentos administrativos como al discurso oficial de los colonizadores y de los cronistas españoles, lecturas a partir de las cuales fundamentó sus relatos sobre la llegada de los europeos y argumentó sus denuncias sobre la exploración instaurada a lo largo del periodo colonial en el Imperio Inca.

En el inicio del capítulo titulado "CONQVISTA" Poma de Ayala narra la llegada de los primeros españoles a la región andina y destaca la fuerte impresióncausada por la apariencia y las costumbres de los extranjeros. De acuerdo con algunos testimonios, los invasores hablaban con sus papeles, quilca, vestían ropas semejantes a mortajas y parecían todos iguales.

Es que decía por queuelauan y que comía plata y oro, ellos como sus caballos. Y que trayýaojotas [sandalias] de plata, decía de los frenos y herraduras y de las armas de hierro y de bonetes colorados. Y que de día y de noche hablauan cada uno con sus papeles, quilca. Y que todos eran amortajados, toda la cara cubierta de lana, y que se le parecía sólo los ojos. Y en la cauesatrayýa unas ollitas colorado, ari manca, y suri uayta [adorno de pluma de avestruz]. Y que trayýan las pixas colgadas atrás larguícimos, decían de las espadas, y que estauanbestidos todo de plata fina. Y que no tenía señor mayor, que todos parecían ermanos en el trage y hablar y conuersar, comer y bestir. Y una cara sólo le pareció que tenía, un señor mayor de una cara prieta y dientes y ojo blanco, que éste solo hablaua mucho con todos.(POMA DE AYALA, p.383)

Según Rolena Adorno, Guaman Poma se apoyó en fuentes orales andinas yen publicaciones europeas sobre la conquista española, como en la "História del descubrimiento del Perú (1555), atribuído a Agustín de Zárate [...] y la Historia del Perú: segunda parte (1571) de Diego Fernández” (ADORNO, 1987, p. XXIII), y en las obras de los religiosos dominicanos Bartolomé de las Casas, Jerónimo de Loaysa y Domingo de Santo Tomás. La utilización de esas fuentes provenientes de la historiografía y de la literatura religiosa españolas tendrían por objetivo facilitar la lectura y comprensión de su texto por el rey Felipe III. 


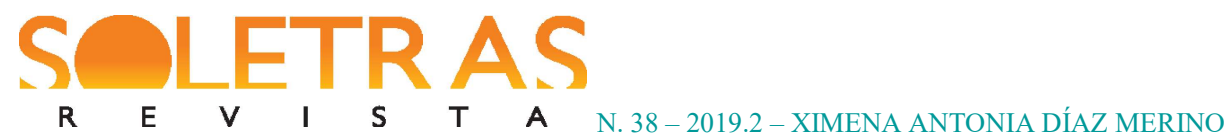

El cronista no hace mención directa a las fuentes utilizadas en su manuscrito, pero registró su admiración por letrados cristianos, como puede ser constatado en el capítulo dedicado a los "Padres de doctrina", cuando escribe: "algunos son grandes cristianos ygrandes letrados y predicadores, y lo fueron desde sus antepasados" o "los de Santo Domingo que son grandícimos letrados y predicadores en el mundo" (POMA DE AYALA, 1615 , p. 383 e p. 618).

En el capítulo titulado "BVEN GOBIERNO”, Poma de Ayala reflexiona sobre la organización colonial impuesta por los españoles en la región andina y propone medidas para mejorar el desempeño de la encomienda y del corregimiento ${ }^{3}$. Entre las críticas al sistema colonial cabe destaque para el confisco de tierra yel robo de propiedades de los indígenas. El cronista consideraba que los españoles debían devolver á sus dueños las tierras robadas o confiscadas, como puede ser observado cuando expresa su preocupación con las acciones de los encomenderos y corregidores:

Cómo don Francisco de Toledo dio orden de proueer corregidor de prouincias en gran daño de los yndiosdesterreyno, cómo se a de perder la tierra por ellos. A causado gran daño y pleytos y perdiciones de los yndios.

Y cómo se perderá la tierra y quedará solitario y despoblado todo el rreyno y quedará muy pobre el rrey. Por causa del dicho corregidor, padre, comendero y demás españoles que rroban a los yndios sus haziendas y tierras y casas y sementeras y pastos y sus mugeresy hijas, por ací casadas o donzellas, todos paren ya mestisos y cholos. Ay clérigo que tiene ueynte hijos y no ay rremedio. (POMA DE AYALA, 1615, p.446).

Para fundamentar sus objeciones al sistema colonial Poma de Ayala se apoyó en los testimonios orales yen documentos de autoría de europeos y criollos. Una de esas fuentes contempladas en la Nueva corónica y buen gobierno e sel Tratado de las doce dudas (1564) en el que Bartolomé de Las Casas denuncia la ilegitimidad de la invasión española y exige la

3La encomienda y el corrigimiento fueron estrategias político-administrativas que el gobierno español implantó en sus colonias para garantizar el dominio imperial y una buena administración. 


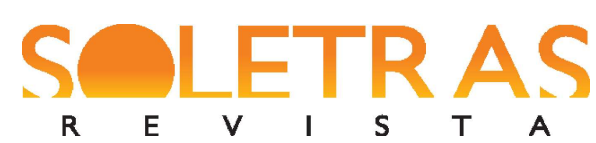

devolución de los territorios usurpados a sus legítimos propietarios indígenas. De acuerdo con Rolena Adorno “el Tratado circuló entre los dominicos en el virreinato peruano; a través de aquellos miembros activos de la orden en Huamanga (hoy Ayacucho), el cronista peruano debió de haberse enterado de la obra.". El "Principio I" del Tratado de Las Casas (1958, p. 486), transcrito a seguir, puede ser identificado claramente en el texto de Guaman Poma, "Principio I: Todos los infieles tienen jurisdicción sobre sus posesiones y territorios: a ello se añaden privilegios de soberanía. Este derecho a la jurisdicción es mandado no sólo por legislación humana [...]. "Ese principio corresponde, en el texto de GuamanPoma,al capítulo titulado “Conzederacion” (POMA DE AYALA, 1615, p.915), en el que escribió

Que aués de conzederar que todo el mundo es de Dios y ancí Castilla es de los españoles y las Yndias es de los yndios y Guenea es de los negros. Que cada déstos son lexítimospropetarios, no tan solamente por la ley, cómo lo escriuió San Pablo que de dies años estaua de pocición y se llamauarromano. [...]

Se observa que mientras Las Casas escribe "Todos los infieles tienen jurisdicción sobre sus posesiones y territorios [...] es mandado no sólo por legislación humana", Guaman Poma declara "Que aués de conzederar que todo el mundo es de Dios y ancí Castilla es de los españoles y las Yndias es de los yndios [...] Que cada déstos son lexítimos propetarios, no tan solamente por la ley”. Guaman Poma continua su manuscrito afirmando que cada uno es propietario de sus tierras en su reino, el español en Castilla y el indio en las Índias, y reivindica los derechos de los indígenas al enfatizar que los españoles son extranjeros en las Índias, pues Dios plantólas semillas del pueblo español en Castilla y las de los índios en las Índias, por lo que unos y otros no deben entrometerse en la otra nación:

Que uien puede ser esta ley porque un español al otro español, aunque sea judío o moro, son españoles, que no se entremete a otra nación cino que son españoles de Castilla. La ley de Castilla, que no es de otra generación [...] Y los yndios son propetarios naturales desterreyno, y los españoles, naturales de España. Acá en este rreyno son estrangeros, mitimays. 


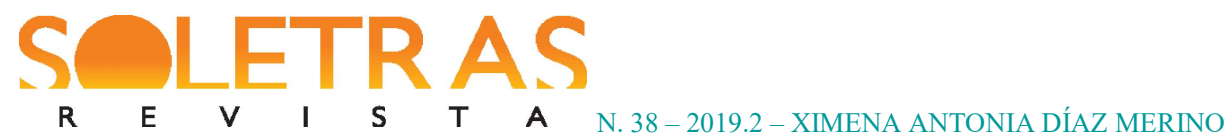

Cada uno en su rreyno son propetarios lexítimos, poseedores, no por el rreycino por Dios y por justicia de Dios: Hizo el mundo y la tierra y plantó en ellas cada cimiente, el español en Castilla, el yndio en las Yndias, el negro en Guynea. [...]. (POMA DE AYALA, 1615, p.915)

Ese fragmento se relaciona claramente conel texto de Las Casas en el "Principio II" que dice que los infieles tienen el derecho de gobernar sus propios territorios. Si los judíos y los morosque vivían en Castilla eran obligados a seguir las leyes locales, de igual forma,l os españoles que vivían en Perú también deberían obedecer a las autoridades autóctonas:

Principio II: los infieles que viven entre cristianos son vasallos de los reyes cristianos, como por ejemplo los judíos y moros que vivian en Castilla estaban obligados a obedecer las justas leyes de ese reino. [...] los indios del Nuevo Mundo. como infieles que nunca usurparon los territorios cristianos ni perjudicaron en alguna forma a las naciones cristianas. poseen sus propios reinos, ejercitan legítimarnente su propia jurisdicción: cualquier intenvención de soberanía extranjera sería una violación de ley natural. (LAS CASAS, 1958, p. 489).

Otra denuncia presentada por Poma de Ayala está relacionada a la extracción de metales preciosos, una de las actividades productivas más devastadoras realizadas durante el periodo de la Colonia. Situación destacada en la ilustración en que se lee "COREGIDOR DE MINAS: CÓMO LO CASTIGA CRVelmente a los caciques prencipales los corregidores y jueses con poco temor de la justicia con deferentes castigos cin tener misericordia por Dios a los pobres" (POMA DE AYALA, 1615, p. 529).

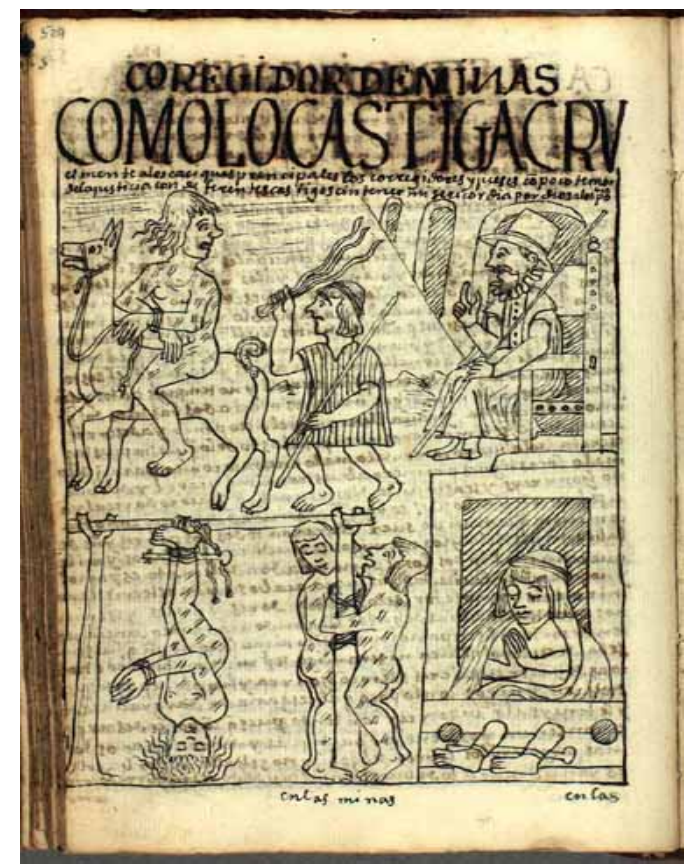

Figura 1 - V Poma de Ayala (1615, p. 529) 


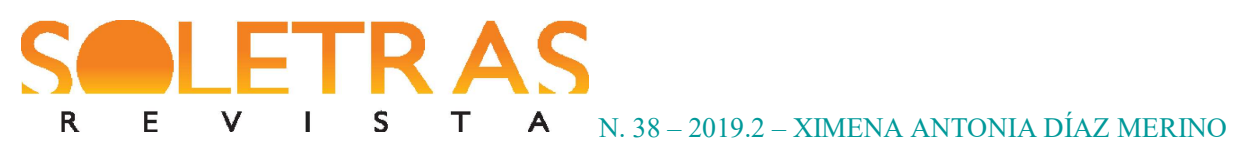

Los dibujos representan los castigos a los que eran sometidos los indígenas que trabajaban en las minas. En la página siguiente presenta el "CAPÍTVLO DE LOS MINEROS", en el que explica que tanto en las minas de oro como en las de plata los indígenas eran maltratados y no recibían remuneración alguna por su trabajo, como transcrito a seguir:

En las dichas minas de Guancabilca de azogue es adonde tiene tanto castigo los yndios pobres y rreciuen tormentos y muchomuerte de yndios. Adonde se acaua y pasa tormentos los caciques prencipalesdesterreyno, acimismoen todas las demás minas de Potocí de plata y de Chocllo Cocha de plata y de Carauayal de oro y minas de otras partes [...] Cuelga de los pies al cacique prencipal y a los demás le asota sobre encima de un carnero y a los demás le ata desnudo en cueros en el rrollo y lo castiga y trisquila. Y a los demás le tiene en la cárzel pública preso en el sepo con grillos cin dalle de comer ni agua y cin dalle lisencia para proueerse. Toda la dicha molestia y afrenta lo haze con color de que falta algunos yndios de la mita [turno en cumplir] [...] Y no le paga su trauajo de la yda y buelta de los caminos y de acudir en las minas, de los tienposquestá y a los yndios de sus jornales. (POMA DE AYALA, 1615, p.530)

Como el propio Guaman Poma registró, en su peregrinación por el virreinato del Perú entró en contacto con las miserias y los problemas enfrentados por los indígenas andinos y de esa forma pudo actuar en su defesa. Consta también que entre la confección del manuscrito y la colecta de informaciones pasaron entre veinte y treinta años,

Pues yo te digo que me a costado treynta años de trauajo ci yo no me engaño, pero a la buena rrazónbeynte años de trauajo y pobresa. Dexando mis casas y hi[j]os y haziendas, e trauajado, entrándome a medio de los pobres y seruiendo a Dios y a su Magestad, prendiendo las lenguas y le[e]r y escriuir, seruiendo a los dotores y a los que no sauen y a los que sauen. (POMA DE AYALA, 1615, p.1105). 


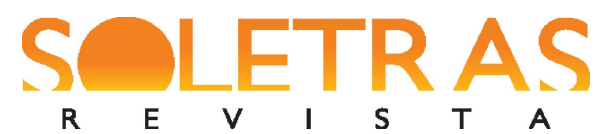

N. 38 - 2019.2 - XIMENA ANTONIA DÍAZ MERINO

A lo largo de esos años Guaman Poma fue formando nuevos discípulos a los que enseñó a leer y a escribir, concientizándolos de las injusticias impuestas por la Colonia. Uno de esos discípulos fue Cristóbal de León, el que fue castigado por un corregidor por defender a las minorías, como ilustrado en el dibujo “COREG[ID]OR TIENE PRESO y amolestado a don Cristóbal de León, segunda persona, porque defendió a los yndios de la prouincia.", en el dibujo se describe la situación con las siguientes palabras:

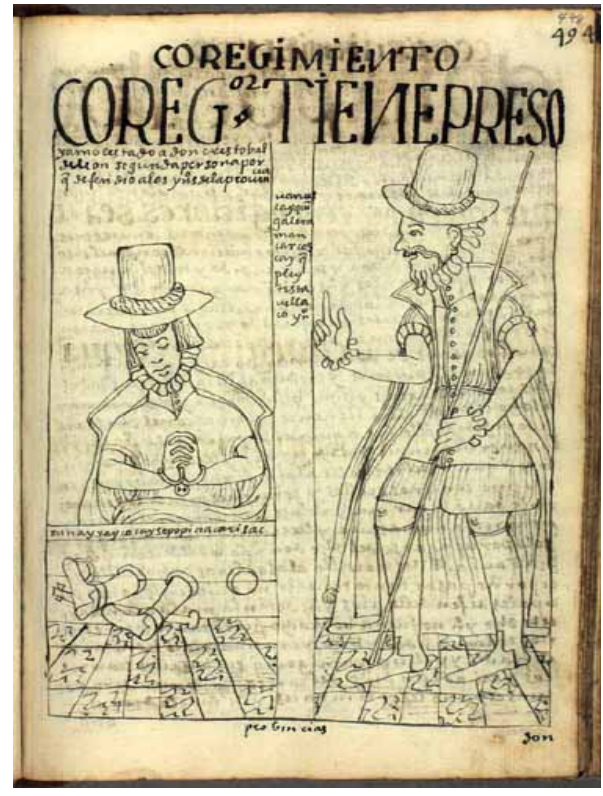

VI Poma de Ayala (1615, p. 498)

/"Uarcuscayqui, galeramancarcoscayqui [Te voy a colgar, te voy a expulsar a las galeras], pleytistauellacoyndio!" / "Runayrayco caysepopinacarisac." ["Por mi gente, yo voy a sufrir en este cepo."] / probincias (POMA DE AYALA, 1615, p.498).

En la página siguiente del manuscrito consta que Cristóbal de León fue castigado, amarrado a un tronco, ameazado con elexílio y la fuerza:

Le prendió este dicho corregidor y le castigó y le afrentó y le quizodesterralle a las galeras. Y le tubo preso en un sepo con unos grillos y con una esposa en las manos. No le daua lugar que hablase con su mugerciquiera y cienpre le amenasaua y le escriuía mentiras a su excelencia, sólo por uengarse del dicho don Cristóbal de León. Y le dezía que auía de desterrallo a las galeras o ahorcallo. (POMA DE AYALA, 1615, p.499).

Además de registrar las injusticias impuestas por la corona española, Guaman Poma dedica el capítulo "De este reino y sus ciudades y villas" a la descripción de ciudades y pueblos por donde pasó. Sobre Cajamarca escribió: 


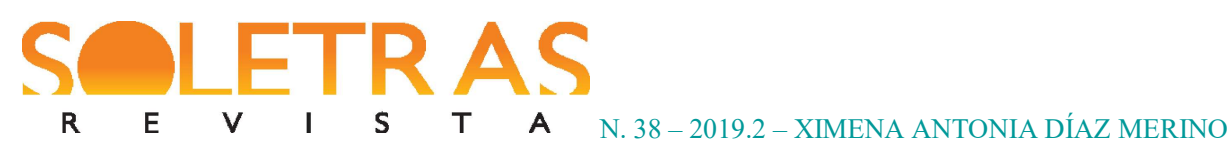

Esta dicha ciudad es de buen tenple y buenos caualleros y bezinos, soldados, yndios. [...] Y tiene mucho juridición y comarcanos y pobre de plata, uastante de oro y rropa de la tierra mucha. [...] Y tienenyglecias y conuentosmuyaderesado, toda policía. $\mathrm{Y}$ se quieren como ermanos y buena justicia y linpios y bien criados ellos como mugeresy hijos en esta ciudad. (POMA DE AYALA, 1615, p.1020).

Guaman Poma describió más de cuarenta ciudades, entre ellas Piscuy

Esta dicha uilla de Piscuy es una uilla bonita pegado a la mar que bate la agua a la uilla y puerto del azogue de Guancabilca para Potocí. [...] Y es tierra mal tenple, calor y frescura de la mar y linda uista y tierra de mucho pescado y poca fruta y poca comida y uino y poca carne y pobre de oro y plata y gente noble y buenos caualleros y bezinos, moradores y soldados, gente de pas, gran seruidor de Dios y de su Magestad [...](POMA DE AYALA, 1615, p.1048).

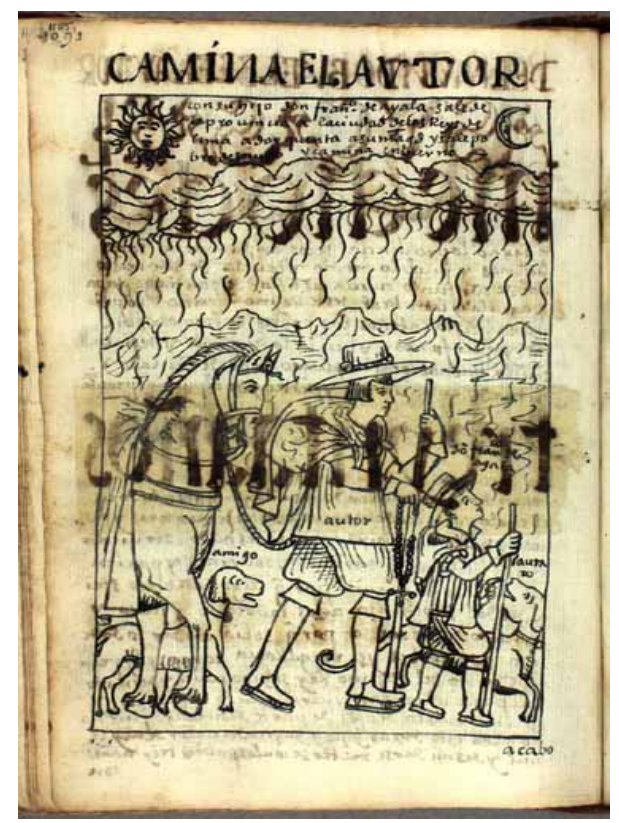

VII Poma de Ayala (1615, p. 1105)
En el capítulo "Camina el autor", Guaman Poma narra su último viaje a Lima para entregar su manuscrito ao representante del rey: "CAMINA EL AVTOR con su hijo don Francisco de Ayala. Sale de la prouincia a la ciudad de los Reys de Lima a dar qüenta a su Magestad. Y sale pobre, desnudo y camina enbierno." (POMA DE AYALA, 1615, p.1105).

En el fragmento DEL MVNDO BVELBE EL AVTOR escribe que hacíatreintaaños que servía a su Majestad, que había alcanzado la edad de ochenta años y que se encontraba viejo y delgado: 


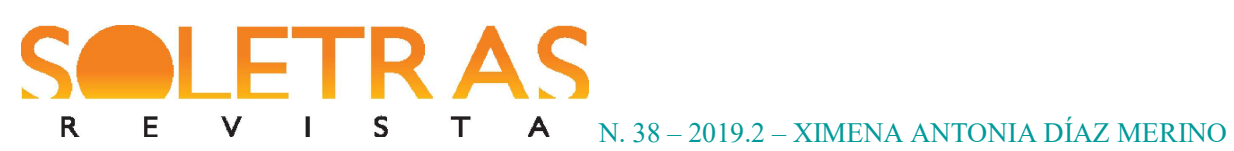

Treynta años estando seruiendo a su Magestad, halló todo en el suelo y entrádole en sus casas y sementeras y pastos. Y halló a sus hijos y hijas desnudo, seruiendo a yndios picheros, Que sus hijos y sobrinos y parientes no le conocieron porque llegó tan biejo; sería de edad de ochenta años, todo cano y flaco y desnudo y descalso. (POMA DE AYALA, 1615, p.1104).

Como constatado, Guaman Poma fue uno de los primeros indígenas ladinos que participó activamente en los debates sobre la invasión y colonización andinas y dejó registrado su testimonio en su crónica. El cronista amerindio utilizó varias formas de codificación e interpretación en su obra, como la transcripción de testimonios orales proporcionados por informantes en diferentes idiomas andinos, lo que resultó en una estructura propia de interpretar el mundo, un proceso que combina y sintetiza las preocupaciones indígenas peruanas con la retórica extranjera española. Puede destacarse la preocupación del autor en explicar el imaginario andino a un público europeo, preservar su cultura, además de divulgar su propuesta de reforma administrativa colonial, llamando la atención especialmente para la devolución de tierras a sus legítimos propietarios.

Al actuar como mediador entre el colonizado yel indígena iletrado, Felipe Guaman Poma de Ayala, un indígena ladino, elabora una significativa obra autoetnográfica permeada de críticas al sistema colonial y de reivindicaciones de justiça social. Por lo tanto, se trata de un indígena letrado, mediador de culturas, que presenta una nueva perspectiva sobre la história colonial andina.

\section{Referências}

ADORNO, Rolena. Felipe Guaman Poma de Ayala. 2010. Disponível em: https://jorgecaceresr.files.wordpress.com/2010/05/sobre-guaman-poma-rolena-adorno.doc.

Acessado em: 05/03/2018.

ADORNO, Rolena. Waman Puma: El autor y su obra. In: Felipe Guaman Poma de Ayala: Nueva crónica y buen gobierno. Ed.John V. Murra, Rolena Adorno y Jorge L. Urioste. Madrid: Historia-16, 1987. pp. XVII-XLVII.

DAGENAIS, John. The Ethics of Reading in Manuscript Culture: Glossing the Libro de buenamor. Princeton: Princeton UniversityPress, 1994. 


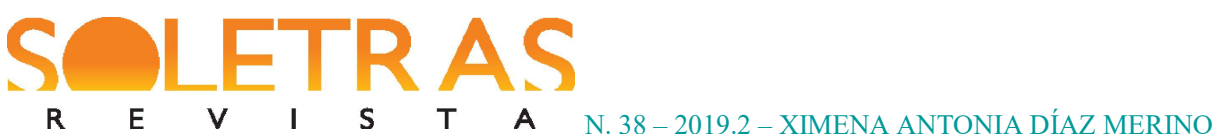

GONZÁLEZ ECHEVARRÍA, Roberto. Mito y archivo: umateoria de la narrativa latinoamericana. Trad. Virginia Aguirre Muñoz. 2a ed. México: F.C.E, 2011.

CASAS, Bartolomé de las. Tratado de las doce dudas. In: Obras escogidas de Fr. Bartolomé de las Casas. Madrid. Ed. Juan Pérez de Tudela Bueso, 1958. pp. 478-536.

MAZZOTTI, José Antonio. Coros mestizos del Inca Garcilaso de la Vega: resonancias andinas.México: Bolsa de Valores de Lima, F.C.E, 1996.

PORRAS BARRENECHEA, Raúl. El cronista indio Felipe Huamán Poma de Ayala (¿15341615?). 1948. In: Indagaciones peruanas: El Legado Quechua.Disponível em http://sisbib.unmsm.edu.pe/BibVirtual/libros/linguistica/legado_quechua/el_cronista.htm.

Acessado em: 11/05/2018.

POMA DE AYALA, Felipe Guaman. Edição Facsimilar: Nueva coronica y buen gobierno, 1615.Disponívelem http://www.kb.dk/permalink/2006/poma/828/es/image/?open=idp283120. Acesso em 16/03/2018.

PRATT, Mary Luise. Ojos Imperiales: literatura de viajes y transculturación. Trad. Ofelia Castillo. México: FCE, 2010.

RAMA, Ángel. La ciudad letrada. Montevideo: Arca, 1998.

RAPPAPORT, Joanne \&CUMMINs, Tom. Más allá de la ciudad letrada: letramientos indígenas em los Andes. Trad. Mercedes López Rodríguez. Bogotá: Editorial Universidad del Rosario, 2016.

VIERECK SALINAS, Roberto. Felipe Guaman Poma de Ayala: cronista indígena, traductor literal. Disponível em: https://cvc.cervantes.es/literatura/aih/pdf/17/aih_17_6_011.pdf. Acesso em: 16 de mar. 2018.

WACHTEL, Nathan. Pensamiento salvaje y aculturación. El espacio y el tiempo de Felipe Guaman Poma de Ayala y el Inca Garcilaso de la Vega. In: Sociedad e ideología: ensayos de historia y antropología andinas. Lima: Instituto de Estudios Peruanos, 1973.

\section{Nueva corónica y buen gobierno i justicia: textualidades, subversãoe resistência em"zonas de contacto"}

Resumo: Os primeiros textos de autoria indígena na América Hispânica constituem parte importante docorpus literário colonial, pois se situamnas denominadas zonas de contacto, ou seja, nos "[...] espacios sociales en que culturas dispares se encuentran, chocan y se enfrentan, a menudo dentro de relaciones altamente asimétricas de dominación y subordinación [...].” (PRATT, 2010, p. 31). Dentro desse contexto será analisada a crônica de Felipe Guaman Poma de Ayala intitulada Nueva corónica y buengobierno i justicia (1615), considerada uma das primeiras fontes escritas por um indígena que narra sua própria versão da história andina. As reflexões aqui apresentadas convergem para a ideia de que o cronista ameríndio elaborou uma obra autoetnográfica permeada de críticas ao sistema colonial e

SOLETRAS - Revista do Programa de Pós-Graduação em Letras e Linguística - PPLIN

Faculdade de Formação de Professores da UERJ

Número 38 (jul.-dez. 2019) - ISSN: 2316-8838

DOI: https://doi.org/10.12957/soletras.2019.43394 


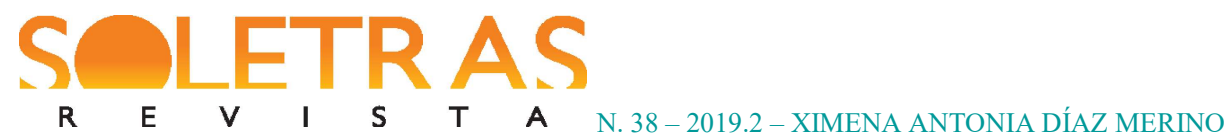

de reivindicações de justiça social manifestadas num documento escrito em língua espanhola e quéchua, no qual se fusiona a escrita e a oralidade. Um manuscrito complementado com ilustrações e epígrafes explicativas con o intuito de traduzir o imagináario andino a um público europeu além de divulgar sua proposta de reforma administrativa colonial. Estudos críticos como os de Wachtel (1973), Pratt (2010), Porras Barrenechea (1948), Adorno (2010) y González Echevarría (2011) subsidiarão as análises deste estudo.

Palavras-chave: Literatura Colonial Hispano-Americana, Felipe Guaman Poma de Ayala, Nueva Crónica y Buen Gobierno.

Recebido em: 16 de junho de 2019.

Aceito em: 22 de agosto de 2019. 